\title{
Genome-wide identification and expression analysis of bZIP transcription factors under abiotic stress in alfalfa (Medicago sativa L.)
}

\author{
Atit Parajuli', Karen A. Sanguinet ${ }^{1 *}$, and Zhiwu Zhang ${ }^{* *}$ \\ 'Department of Crop and Soil Science, Washington State University, Pullman, WA 99164, USA \\ Correspondence should be addressed to KS (karen.sanguinet@wsu.edu) or ZZ \\ (zhiwu.zhang@wsu.edu)
}

\section{Abstract}

Alfalfa (Medicago sativa L.) is the most cultivated forage legume around the world. Under a variety of growing conditions, forage yield in alfalfa is stymied by biotic and abiotic stresses including heat, salt, drought, and disease. Given the sessile nature of plants, they use strategies such as differential gene expression to respond to environmental cues. Transcription factors control the expression of genes that contribute to or enable tolerance and survival during periods of stress. Basic-leucine zipper (bZIP) transcription factors have been demonstrated to play a critical role in regulating plant growth and development as well as mediate the responses to abiotic stress in several species, including Arabidopsis thaliana, Oryza sativa, Lotus japonicus and Medicago truncatula. However, there is little information about bZIP transcription factors in cultivated alfalfa. In the present study, 237 bZIP genes were identified in alfalfa from publicly available sequencing data. Multiple sequence alignments showed the presence of intact bZIP motifs in the identified sequences. Based on previous phylogenetic analyses in Arabidopsis thaliana, alfalfa bZIPs were similarly divided and fell into 10 groups. The physico-chemical properties, motif analysis and phylogenetic study of the alfalfa bZIPs revealed high specificity within groups. The differential expression of alfalfa bZIPs in a suite of tissues indicates that particular bZIP genes are specifically expressed at different developmental stages in alfalfa. Similarly, expression analysis in response to ABA, cold, drought and salt stresses, indicates that a subset of bZIP genes are also differentially expressed and likely play a role in abiotic stress signaling and/or tolerance. However, further functional characterization of bZIP transcription factors in alfalfa will help illuminate the role they play in stress tolerance mechanisms in legumes and facilitate the molecular breeding of stress tolerance in alfalfa.

Keywords: Alfalfa, bZIP transcription factor, phylogenetic analysis, expression pattern, abiotic stress 


\section{Introduction}

Alfalfa (Medicago sativa L.) is a perennial and highly outcrossing forage legume crop grown predominantly for hay, silage, and pasture. It is the most widely cultivated forage legume in the United States with approximately 16 million hectares planted (USDA-NASS, 2018). The high nutritional value of alfalfa with about $15-22 \%$ crude protein and an abundance of vitamins and minerals makes it well suited for animal and livestock feed. Alfalfa also brings long-term ecological benefits to society by improving soil fertility through its symbiotic association with the soil bacterium Sinorhizobium meliloti for atmospheric nitrogen fixation, which augments the nitrogen content in the soil for future crops (Carelli et al., 2000; Pellock et al., 2000; Donnarumma et al., 2014). The perennial nature of alfalfa along with its deep root system (up to $15 \mathrm{~m}$ ) helps to prevent soil erosion. However, genetic improvement in terms of forage yield has been relatively stagnant in alfalfa (USDA-NASS, 2018).

In fact, the high out-crossing nature, genomic complexity, severe inbreeding depression upon selfing and self-incompatibility complicates alfalfa breeding. Although the multi-purpose use of alfalfa is increasing in demand, production is hindered by changing environmental conditions leading to abiotic stresses like heat, drought, and salinity. In the context of stagnant genetic improvement, cultivation of stress-resilient alfalfa germplasm will help to improve production in response to climate change. However, identification of stress-resilient germplasm requires identification of stress-responsive genes, which, in alfalfa, are very few due to incomplete genomic information and limited expression profile data.

The sessile nature of plants inevitably exposes them to adverse environmental conditions such as abiotic stress. Plants have developed diverse mechanisms to cope with these abiotic stresses. One mechanism is the synthesis of proteins, metabolites, and other compounds to aid in survival through abiotic stress, which are often controlled by transcription factors (TFs). Transcription factors play a critical role in responses to environmental stresses via binding to cis-regulatory elements in promoters to regulate downstream gene expression. In plants, approximately $7 \%$ of the genome codes for transcriptional regulators, which bind promoter elements of downstream genes through their conserved sequence specific DNA-binding domain (Udvardi et al., 2007). Among the 64 families (Pérez-Rodríguez et al., 2010) of transcription factors identified in the plant kingdom, the bZIP (basic leucine zipper) family is one of the largest and most diverse (Nijhawan et al. 2008; Pérez-Rodríguez et al., 2010; Dröge-Laser et al., 2018).

The basic leucine zipper (bZIP) family is distinguished by its highly conserved bZIP domain composed of $60-80$ amino acids (Hurst, 1994). Structurally, the bZIP domain is divided into two functionally distinct regions: a basic region and a leucine zipper motif (Hurst, 1994). The basic region is composed of an invariant motif $(\mathrm{N}-\mathrm{x} 7-\mathrm{R} / \mathrm{K}-\mathrm{x} 9)$ of 18 amino acids residues that facilitates sequence-specific DNA binding, while the leucine zipper contains several heptad repeats of leucine or other bulky hydrophobic amino acids such as isoleucine, valine, phenylalanine, or methionine, for dimerization specificity (Jakoby et al., 2002; Nijhawan et al., 2008). Molecular studies of bZIP genes in Arabidopsis thaliana show that they are involved in the regulation of diverse biological processes including pathogen defense, light and stress signaling, seed maturation and flower development (Jakoby et al., 2002). Additional information on the bZIP transcription factor family has provided evidence of their role in response to biotic and abiotic stresses in a diversity of plant species (Jakoby et al., 2002; Wei et al., 2012). 
The availability of whole genome sequences for plants allows the identification or prediction of bZIP TF family members at the genome-wide level. The number of bZIP TFs identified in different plant and crop species varies from 78 (AtbZIPs) in Arabidopsis thaliana (Dröge-Laser et al., 2018; Jakoby et al., 2002), 89 (OsbZIPs) in Oryza sativa subs. japonica (Nijhawan et al., 2008), 125 (ZmbZIPs) in Zea mays (Wei et al., 2012), 131 (GmbZIPs) in Glycine max (Liao et al., 2008), 92 (SbbZIPs) in Sorghum bicolor (J. Wang et al., 2011), 55 (VvbZIPs) in Vitis vinifera (J. Liu et al., 2014), 64 (CsbZIPs) in Cucumis sativus (Baloglu et al., 2014) and 247 (BnbZIPs) in Brassica napus (Y. Zhou et al., 2017). The bZIP transcription factors play crucial roles in developmental processes and environmental tolerance in response to multiple stresses. They are involved in the regulation of seed development (Izawa et al., 1994; Toh et al., 2012), cell elongation (Fukazawa et al., 2000; Yin, 1997), vascular development (Yin, 1997), flower development (Abe et al., 2005; Chuang et al., 1999; Gibalová et al., 2009; Iven et al., 2010), somatic embryogenesis (Guan et al., 2009), as well as in nitrogen/carbon and energy metabolism (Baena-González et al., 2007; Ciceri et al., 1999; Weltmeier et al., 2006).

In addition to functions in plant growth and development, bZIPs also play an important role in responses to abiotic and biotic stresses. Several bZIPs from A. thaliana (AtbZIP17, AtbZIP24, AtbZIP12), rice (OsbZIP12, OsbZIP72, OsABF1) and soybean (GmbZIP44, GmbZIP62, GmbZIP78) were found to positively regulate salt stress adaptation in plants either directly or indirectly (Amir Hossain et al., 2010; Hossain et al., 2010; Ji et al., 2013; Liao et al., 2008; LIU et al., 2008; Lu et al., 2009; O. Yang et al., 2009). Several bZIPs from rice (OsbZIP52/RISBZ5, OsbZIP16, OsbZIP23, OsbZIP45, AREB1, AREB2, ABF3) were also found to be involved in drought tolerance (Hao Chen et al., 2012; C. Liu et al., 2012; Park et al., 2015; Yoshida et al., 2010). OsbZIP52/RISBZ5 negatively regulates cold stress responses (C. Liu et al., 2012) while OsbZIP72 was a positive regulator of ABA responses (Lu et al., 2009). Similarly, overexpression of GmbZIP44, GmbZIP62 and GmbZIP78 reduced ABA sensitivity (Liao et al., 2008). Interestingly, group D or so-called TGA bZIPs plant a role in systemic acquired resistance (SAR) and pathogen resistance (Fu \& Dong, 2013; Gatz, 2013). However, there is little published information about the bZIP transcription factor family in cultivated alfalfa and its role in stress resistance.

With the availability of a chromosome-level genome assembly in alfalfa (Chen et al., 2020) we conducted a genome-wide search to identify and characterize the alfalfa bZIP transcription factors. Since bZIP transcription factors were identified to play significant roles in the regulation of abiotic stress tolerance (Jakoby et al., 2002; Wei et al., 2012), we speculated various bZIP transcription factors would be differentially expressed throughout distinct developmental stages and abiotic stresses in alfalfa as well. The present study identifies several bZIPs from a proteomic database in tetraploid alfalfa (Medicago sativa). We also analyzed differential gene expression from transcriptome sequences during ABA, drought, salt, and cold stress conditions. This study will facilitate functional analysis of the bZIP transcription factor family in alfalfa. The identification of functions of alfalfa bZIP transcription factors during abiotic stress conditions will further help breeding efforts for improved stress tolerance. 


\section{Materials and Methods}

Identification of bZIP transcription factor gene family in alfalfa

For comprehensive identification and analysis of the bZIP transcription factor (TF) gene family in alfalfa, the sequences of bZIP transcription factors from model and known species were downloaded from the Plant Transcription factor database (http://planttfdb.cbi.pku.edu.cn/), which included 127 sequences from Arabidopsis thaliana, 93 from Lotus japonicus, 124 from Medicago truncatula and 140 from Oryza sativa. The number of bZIPs used were more than that is mentioned in Table 1 as it included spliced variants as well. A local protein database was created using Basic Local Alignment Search Tool (Altschul et al., 1990) with protein sequences from chromosome level assembly of alfalfa (Haitao Chen et al., 2020). A BLASTp search was conducted in the local database created using the protein sequences from alfalfa, taking the bZIP sequences from model organisms as a query with an E-value cut-off of 1E-05 (0.00001). The bZIP sequences obtained from the search were further confirmed based on the presence of the bZIP domain $(\mathrm{N}-\mathrm{x}(7)-\mathrm{R} / \mathrm{K}-$ $x(9)-L-x(6)-L-x(6)-L)$ using the Pfam web program (https://pfam.xfam.org/) with an E-value of 1.0. Further, the bZIP domain was used to search against the database of the identified bZIP sequences using the Prosite program of the ExPASy bioinformatics resource (http://protsite.expasy.org). The identified sequences with intact bZIP domains were predicted to be bonafide bZIP sequences.

Evolutionary analysis, protein properties and detection of conserved motifs in the bZIPs

To analyze the sequence features of bZIP transcription factors, multiple sequence alignment of 237 bZIP proteins were performed using multiple sequence comparison by log-expectation (MUSCLE) (Edgar, 2004) command using default parameters. The output of the multiple sequence alignment was visualized using Unipro UGENE v.33. For evolutionary analysis, 549 sequences were used which included sequences from Medicago sativa (237), Arabidopsis thaliana (78), Lotus japonicus (70), Medicago truncatula (75) and Oryza sativa (89). Multiple sequence alignment was carried out by CLUSTALW with default parameters. Subsequently, the phylogenetic tree was constructed by the Neighbor Joining method using 1000 bootstraps replicates. Phylogenetic analyses were conducted using MEGA version X (Kumar et al., 2018).

Other physical properties of the identified sequences like the molecular weight and theoretical isoelectric point $(\mathrm{pI})$ were determined using Compute $\mathrm{pI} / \mathrm{Mw}$ tools (http://web.expasy.org/compute_pi/) of ExPASy bioinformatics resource. The MEME (Timothy L. Bailey et al., 2015) program was used to identify the conserved motifs within the full-length Alfalfa. The parameters used were maximum number of motifs to be 25 , distribution of motifs $=$ any number of repetitions, optimum motif width $=6$ to 50 residues.

In silico functional analysis of bZIP genes

For predicting the MsbZIP protein function (gene ontology) GO annotation was performed using the web-accessible Blast2GO v4.1 annotation system (https://www.blast2go.com/) (Conesa \& Götz, 2008). Briefly, the MsbZIP protein sequences were used to search for similar sequences against the NCBI non-redundant (Nr) database using the Blast tool in the Blast2GO software, with an E-value of 10-3 (1e-03). Next, mapping and annotation were performed on Blast2GO using default parameters. Finally, functional classification was also performed by Blast2GO. 


\section{Expression analysis during plant development}

The raw RNA sequence data was downloaded from the National Center for Biotechnological Information (NCBI) Sequence Read Archive (SRA), SRP055547 (O'Rourke et al., 2015). The data was generated from six tissues at different growth stages of Alfalfa namely, root, nodule, elonged stem, pre-elonged stem, leaf, and flower. The tissue sample for RNA-Seq was collected at the respective stage of alfalfa plants. Fastqc version 0.11.7 was used for quality check of the raw sequences. The reads passing the minimum Phred quality score of 30 were selected. The RNASeq analysis was carried out following the method described by (Pertea et al., 2016), in which the filtered reads were aligned with the reference genome using HISAT2 version 2.1.0 (Kim et al., 2015) and sorted by Samtools ver 1.9. Transcript assembly and quantification was carried out using Stringtie version 2.1.1 (Pertea et al., 2015). A python script was used to extract read count information directly from the files generated from Stringtie and edgeR package (Robinson et al., 2010) in $R$ was used for differential gene expression analysis. TBtools version 1.0692 (C. Chen et al., 2020)was used to generate heatmaps for the differentially expressed genes.

\section{Transcriptome analysis of bZIP genes in response to abiotic stresses}

The raw RNA sequence data from previous studies were downloaded from the National Center for Biotechnological Information (NCBI) Sequence Read Archive (SRA). The transcriptome data consist of cold treatment (SRR7091780-SRR7091794,(Q. Zhou et al., 2018), and ABA, drought, and salt treatments (SRR7160313-SRR7160357, (Luo et al., 2018, 2019). All of these samples were collected from 12 days old alfalfa seedlings for RNA-Seq. Fastqc version 0.11.7 was used for quality check of the raw sequences. The reads passing the minimum Phred quality score of 40 were selected. The RNA-Seq analysis was carried out following the method described by (Pertea et al., 2016), in which the filtered reads were aligned with the reference genome using HISAT2 ver2.1.0 and sorted by Samtools ver1.9. Transcript assembly and quantification was carried out using Stringtie version 2.1.1. A python script was used to extract read count information directly from the files generated from Stringtie and edgeR package in $\mathrm{R}$ was used for differential gene expression analysis. TBtools version 1.0692 was used to generate heatmaps for the differentially expressed genes.

\section{Analysis of cis-regulatory elements}

For this analysis, the bZIP genes with changed expression during abiotic stress were visualized using Integrated Genome Browser 9.1.4 (Freese et al., 2016) to locate the promoter sequences. Samtools (ver. 1.9) was used to extract the 2000 base pair sequence from the promoter of these changed bZIP genes to investigate the potential cis-regulatory elements by querying them through the PlantCARE database (http://bioinformatics.psb.ugent.be/webtools/plantcare/html/). In total six cis-regulatory elements responsive to stress were analyzed. These elements included abscisic acid responsive (ABRE), methyl jasmonate responsive (CGTCA-motif), light inducible G-box motif, low-temperature responsive (LTR), drought responsive (MBS binding site) and defense and stress responsive (TC-rich repeats). 


\section{Results}

Identification of the alfalfa bZIP gene family

We identified 237 bZIP sequences with the intact bZIP domain in alfalfa (Medicago sativa). These sequences were named MsbZIP1 to MsbZIP237 based on the order identified in the protein sequence database (Haitao Chen et al., 2020). We compared the genome size and number of bZIPs in different models and crop species (Table 1). The comparison shows that alfalfa has the highest number of bZIP sequences. Since the diploid model legume Medicago truncatula with genome size of 390 Mega Base (Mb) has 75 bZIP sequences, tetraploid alfalfa is expected to have double the number of bZIP sequences. Not surprisingly, the number of bZIP TFs identified in alfalfa was 237, which likely represents the complete number of bZIP for tetraploid alfalfa.

Table 1: Comparative genome size and number of bZIP proteins in different model crops used in the study

\begin{tabular}{|c|c|c|c|}
\hline Species & Chromosome & Genome Size & Number of bZIPs \\
\hline$\frac{\text { Arabidopsis thaliana }}{\text { (Dröge-Laser et al., 2018; Jakoby et al., 2002) }}$ & $2 \mathrm{n}=2 \mathrm{x}=10$ & $135 \mathrm{Mb}$ & 78 \\
\hline$\frac{\text { Brassica napus }}{\text { (Zhou et al. 2017) }}$ & $2 n=2 x_{1}+2 x_{2}=38$ & $1.16 \mathrm{~Gb}$ & 247 \\
\hline$\frac{\text { Lotus japonicus }}{\text { (Pérez-Rodríguez et al., 2010) }}$ & $2 n=2 x=12$ & $470 \mathrm{Mb}$ & 70 \\
\hline$\frac{\text { Medicago truncatula }}{\text { (Zhang et al. 2015) }}$ & $2 n=2 x=16$ & $390 \mathrm{Mb}$ & 75 \\
\hline$\frac{\text { Oryza sativa }}{\text { (Nijhawan et al. 2008) }}$ & $2 \mathrm{n}=2 \mathrm{x}=20$ & $430 \mathrm{Mb}$ & 89 \\
\hline Medicago sativa & $2 n=4 x=32$ & $3,150 \mathrm{Mb}$ & 237 \\
\hline
\end{tabular}

Multiple Sequence Alignment and Phylogenetic Analysis

To identify common conserved domains amongst the sequences, we carried out multiple sequence alignment. The alignment of $237 \mathrm{bZIP}$ protein sequences showed the presence of intact and highly conserved bZIP domains (N-x(7)-R/K-x(9)-L-x(6)-L-x(6)-L) (Figure 1, Supplementary Figure 1). The domain is divided into the basic region with $\sim 18$ amino acids residues containing nuclear localization signal followed by an intact $\mathrm{N}-\mathrm{x}(7)-\mathrm{R} / \mathrm{K}$ motif while the leucine zipper region contains heptad repeats of leucines or other bulky hydrophobic amino acids with nine amino acids towards the C-terminus (Jakoby et al., 2002). The presence of the intact bZIP domain further validates the identified sequences as bZIP proteins. The identified 237 bZIP proteins were divided into 10 groups (A, C, D, E, F, G, H, I, M, and S) based on the topology of the tree developed in Arabidopsis thaliana (Dröge-Laser et al., 2018; Jakoby et al., 2002) and were used to generate a phylogenetic tree along with protein sequences from Arabidopsis thaliana, Lotus japonicus, Medicago truncatula and Oryza sativa (Fig. 2). Alfalfa bZIP proteins fell into 10 different groups and numbers ranged from four $(\mathrm{H})$ to forty-three $(\mathrm{A})$; however, no members were identified for groups $\mathrm{B}, \mathrm{J}$ and $\mathrm{K}$. 


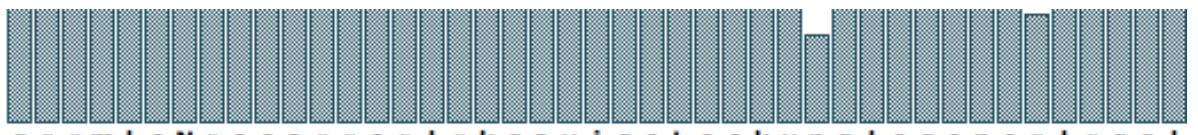

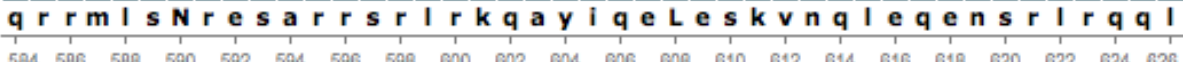

MSbZIP3

MsbZIP6

MSbZIP7

MSbZIPI 7

MSbZIP2O

MsbZIP29

MSbZIP4O

MsbZIP42

MsbZIP44

MsbZIP60

MsbZIP63

MsbZIP67

MsbZIP68

MSbZIP76

MsbZIP78

MsbZIP80

MsbZIP83

MsbZIP88

MsbZIP89

MsbZIP94

MsbZIPIOO

MsbZIPI11

MsbZIP1 15

MsbZIP121

MsbZIP126

MsbZIP1 32

MsbZIP136

MsbZIP137

MsbZIP1 39

MsbZIP145

MsbZIP149

MSbZIP158

MsbZIP161

MsbZIP165

MsbZIP175

MsbZIPI82

MsbZIP206

MsbZIP207

MsbZIP216

MSbZIP221

MSbZIP231

MSbZIP233

MSbZIP235

QKRMIKNRES A A RSRAR KQA Y T Q ELE I KVSHLEEENERLKRLH

QKRMIKNRESAARSRARKQAYTNELEVKVSRLEEENEMLRK-.

QKRMIKNRESAARSRARRQAYTQELELKVSRLEE ENERLRRQN

QRRMIKNRESAARSRARKQAYTVELEAELNQLREENSQLKQAL

QKRMIKNRESAARSRARKQAYTQELEIKVSHLEE ENERLKRLH

QRRMLKNRESAARSRARRQAYTLELEAELNLLKE ENQKLKQVL

QKRMIKNRESAARSRARKQAYTTELEIKVSRLEEENEKLRKEK

QKRMIKNRESAARSRARKQAYTTELEIKVSRLEEENEKLRKEK

QKRMIKNRESAARSRERKQAYTTELESLVKHLEIENKQLEEEQ

QKRMIKNRESAARSRARRQAYTQELELKVSRLEEENERLRRQN

QKRMAKNRESAARSRAKKQEHIN KLQMDKFQLEEKNTELKLIK

QKRMIKNRESAARSRARKQAYTNELEIKVSRLEE ENEMLRKRK

QRRMLKNRESAARSRARRQAYTLELEAELNLLKEENEKLKQVL

QRRMLKNRESAARSRARRQAYTLELEAELNLLKEENENLKQVL

QRRMIKNRESAARSRERKQAYQVELESLAVKLEEENDKLMKEK

QRRMIKNRESAARSRERKQAYQVELESLAVKLEEENDKLMKEK

LRRKI KNRESAARSRARKQAYHNELVTKVTLLEQQNMQLKK-

QKRMIKNRES A A R S RERKQAYTTELESLVKHLEIENKQLEEEQ

QRRMIKNRESAARSRARKQAYTMELEAEVAKLKEENEELQKKQ

LRRKIKNRESAARSRARKQAYHNELVTKVTLLEQQNMQLKKEK

QKRMIKNRESAARSRARRQAYTQELELKVSRLEEENERLRRQN

QRRMMKNRESAARSRARRQAYTIELEAELNLLQEENKMLKQFL

$Q K R M I K N R E S A A R S R A R K Q A Y T Q E L E I K V S H L E E E N E R L K R L H$

LRRKIKNRESAARSRARKQAYHNELVTKVTLLEQQNMQLKKEK

LRRKIKNRESAARSRARKQAYHNELVTKVTLLEQQNMQLKKEK

QKRMIKNRESAARSRARKQAYTVELEAEVAKLKEVNEELQRKQ

QKRMIKNRESAARSRARKQAYTTELEIKVSRLEEENEKLRKEK

QRRMIKNRESAARSRARKQAYTMELEAEVAKLKEENEELQKKQ

QRRMMKNRESAARSRARRQAYTIELEAELNLLQE ENKMLKQFL

QRRMMKNRESAARSRARRQAYTIELEAELNLLQEENKMLKQFL

QRRMIKNRESAARSRARKQAYTMELEAEVAKLKEENEELQKKQ

QKRMIKNRESAARSRERKQAYTTELESLVKHLEIENKQLEEEQ

QRRMMKNRESAARSRARRQAYTIELEAELNLLQEENKMLKQFL

QKRMIKNRESAARSRARKQAYTTELEIKVSRLEEENEKLRKEK

QRRMLKNRESAARSRARRQAYTLELEAELNLLKEENENLKQVL

QRRMIKNRESAARSRERKQAYQVELESLAVKLEE ENDKLMKEK

QKRMIKNRESAARSRARKQAYTQELEIKVSHLEEENERLKRLH

QRRMIKNRESAARSRARKQAYTMELEAEVAKLKEENEELQKKQ

QRRMIKNRESAARSRARKQAYTMELEAEVAKLKEENEELQKKQ

QKRMIKNRESAARSRARKQAYTVELEAEVAKLKEVNEELQRKQ

QKRMIKNRESAARSRARKQAYTVELEAEVAKLKEVNEELQRKQ

QRRMIKNRESAARSRERKQAYQVELESLAVKLEEENDKLMKEK

QKRMIKNRESAARSRARKQAYTNELEIKVSRLEEENEMLRKRK

Figure 1: Multiple sequence alignment of alfalfa bZIP proteins of group $\mathrm{S}$. The alignment was performed using MUSCLE 3.8.31 and visualized using Unipro UGENE v.33. The S group contains 32 bZIPs in alfalfa, which are highly expressed during abiotic stress. A consensus sequence is provided at the top of the figure (in bold). The bars above the consensus sequence present the percentage of consensus amino acid base between the aligned sequences. The ruler below the consensus sequence provides the position of the amino acid base on the aligned sequences. The color changes from light to dark with dark color indicating highly conserved amino acid bases. The consensus sequence at the top indicates the level of conservation with a capital letter indicating high conservation and a small letter with low conservation. The highly conserved bZIP domain (N-x(7)-[RK]-x(9)-L-x(6)-L-x(6)-L), between 590 to 622, is presented in dark color. 


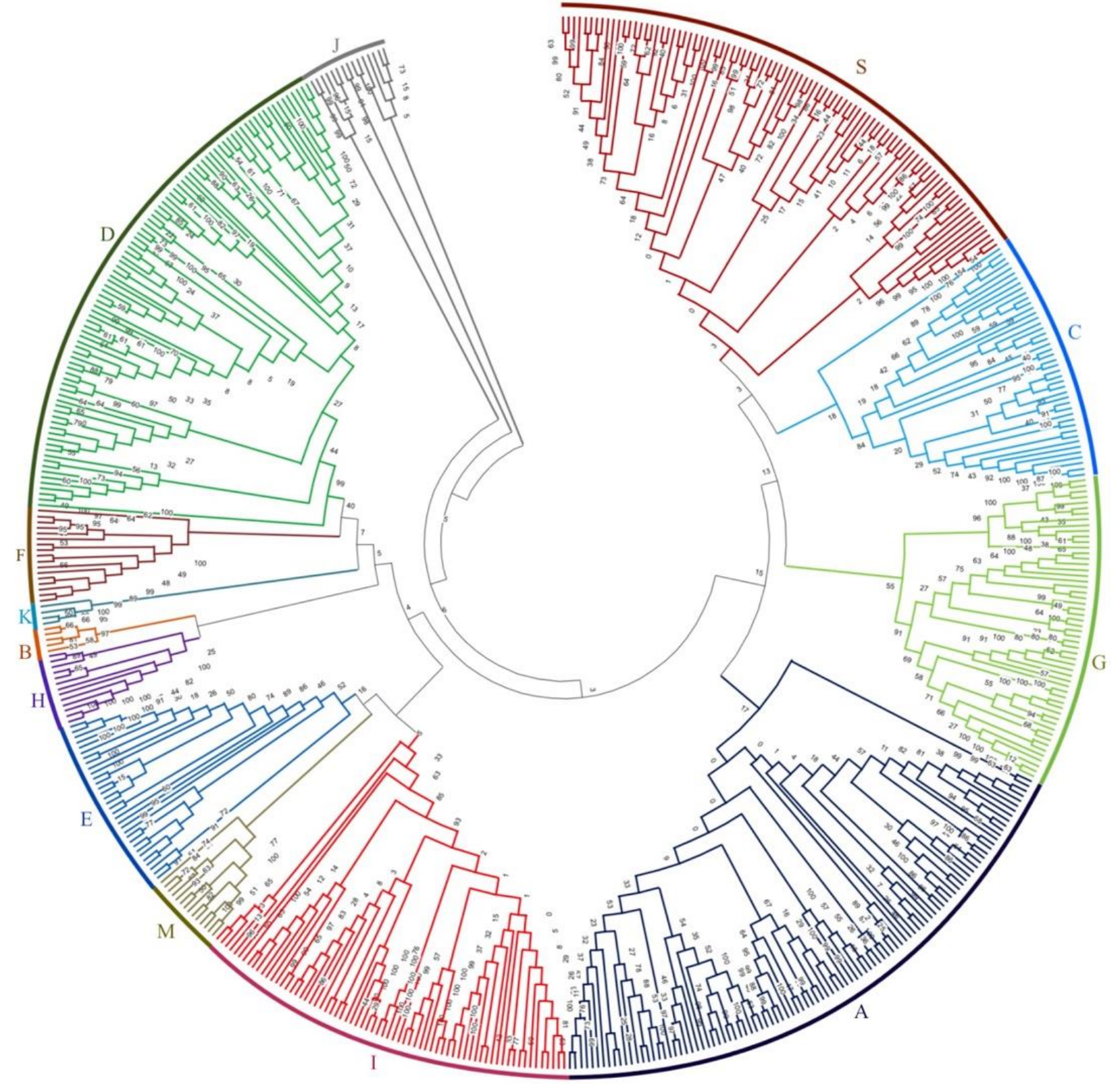

Figure 2: Phylogenetic analysis and group classification of bZIP proteins from alfalfa. 237 bZIP proteins and 312 proteins from Arabidopsis thaliana (78), Lotus japonicus (70), Medicago truncatula (75) and Oryza sativa (89) were used to create a neighbor joining tree with 1000 bootstraps. The bZIPs are grouped into 11 groups (A - K, M and S) based on tree topology results from Arabidopsis thaliana and Medicago truncatula. A detailed information of the tree including the genes from all the species mentioned above is presented in Genes expressed during stress conditions are distributed throughout the groups. Group D contained genes highly expressed during drought stress conditions and ABA, while Group I and S contained genes that are upregulated during salt stress conditions. Although genes highly expressed during cold stress conditions were distributed over different groups, most of them were from group A and S. The detailed information with the gene is presented in Supplement Figure (S6).

\section{Conserved protein domain analysis}

Identification of conserved protein motifs helps to elucidate protein functions and bZIPs usually possess additional conserved motifs that could provide sites for activation (Y. Yang et al., 2019). 
Using the "MEME" (Multiple Em for Motif Elicitation) program (T. L. Bailey et al., 2009), 25 conserved motifs were identified in the 237 bZIPs (Supplementary Table 2). Among the identified motifs, the basic region of the bZIP, containing an invariant motif $(\mathrm{N}-\mathrm{x} 7-\mathrm{R} / \mathrm{K}-\mathrm{x} 9)$ with 18 amino acid residues was found (Figure 3A), while the leucine zipper region that contains the heptad repeat of leucine or other bulky hydrophobic amino acids was also identified (Figure 3B). The basic region facilitates sequence specific DNA binding whereas the leucine zipper region is important for dimerization specificity. However, the function of the 23 motifs that were also identified in the bZIP sequences are unknown and require further study.

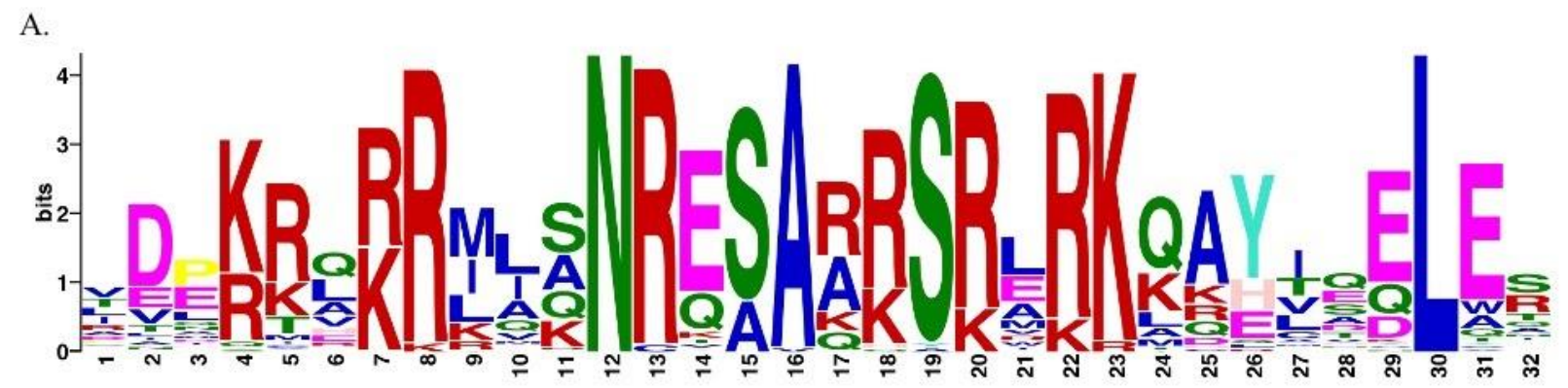

B.

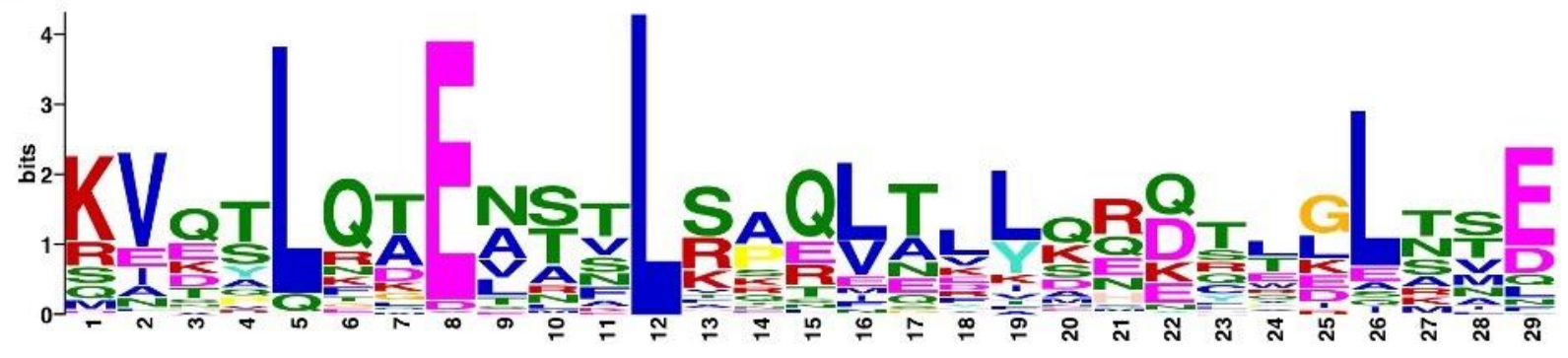

Figure 3: Conserved bZIP domain. (A) the conserved basic region of the bZIP motif (motif 12-29). The basic region is composed of an invariant motif $(\mathrm{N}-\mathrm{x} 7-\mathrm{R} / \mathrm{K}-\mathrm{x} 9)$ with 18 amino acid residues which can be observed. The basic region facilitates the sequence specific DNA binding. (B) The leucine zipper region that contains the heptad repeat of leucine (motif 5-19) or other bulky hydrophobic amino acids is represented by the figure. This region is important as it facilitates the dimerization specificity. This consensus sequence was generated using MEME suite 5.3.3. MEME (Multiple Em for Motif Elicitation) allows discovery of novel motifs in collection of nucleotides or protein sequences. The height of the character corresponds to how frequently the character occurs at that position in the motif.

\section{In silico functional classification of MsbZIP transcription factors}

Among the 237 MsbZIP, 21 GO categories were assigned to 203 of the MsbZIPs identified (Figure 4). The major molecular functions of these bZIPs were DNA-binding transcription factor activity, which is consistent with their demonstrated role as transcription factors in other species. In the biological process category, most of bZIPs were assigned to the regulation of transcription category and almost all of these proteins were predicted to localize to the nucleus in the cellular component category. Transcription factors provide binding sites through which they can regulate gene expression. They may act as either positive or negative regulators of downstream genes depending upon the environmental condition. The current functional classification (GO terms) of these bZIP proteins further supports their regulatory nature. 


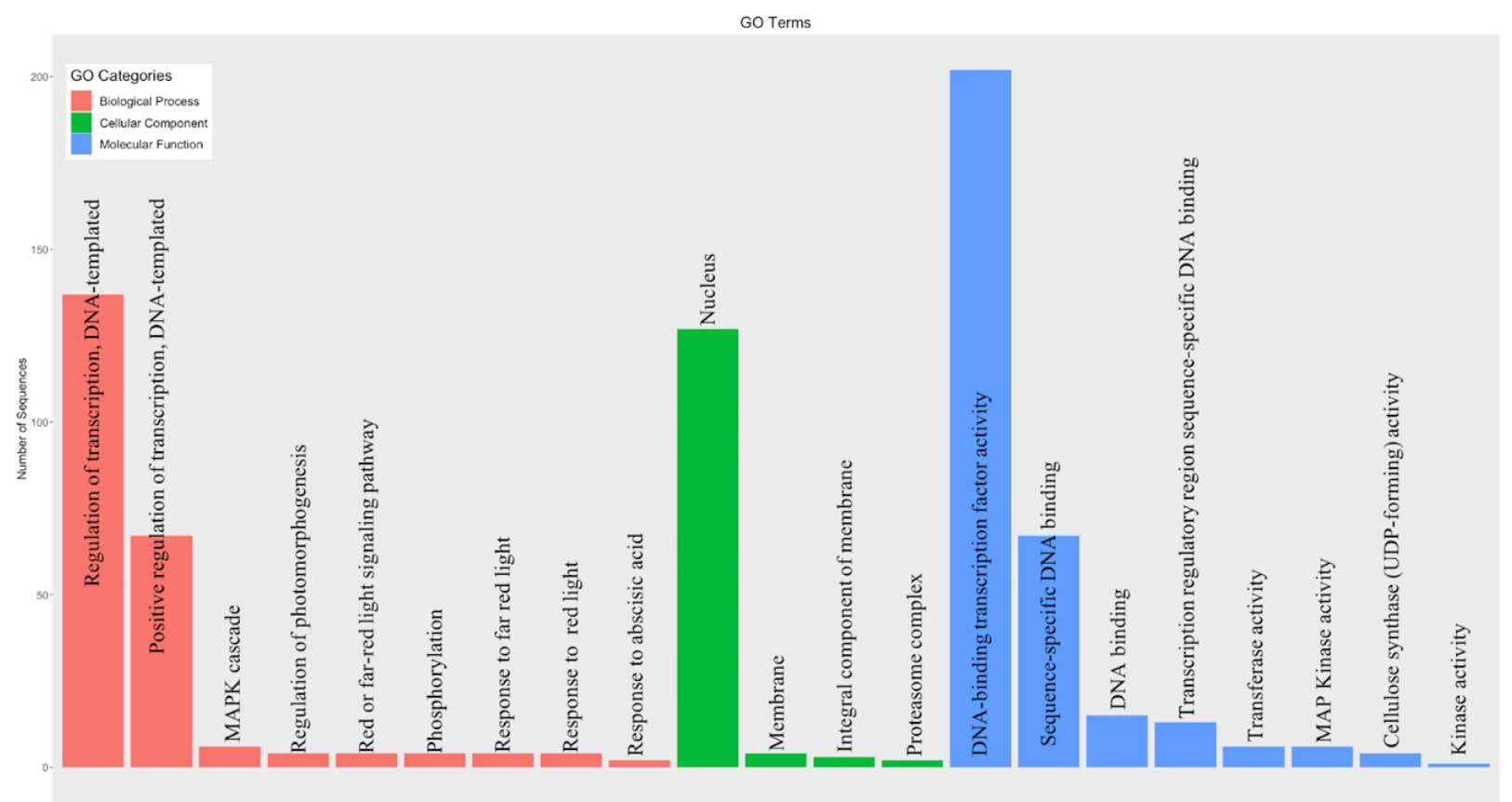

Figure 4. Functional annotation of bZIP proteins in alfalfa. Distribution of genes in different GO categories for Biological Process (pink), Cellular Component (green) and Molecular Function (blue). In the molecular function category, most of the genes were assigned to DNA binding transcription factor activity followed by sequence-specific DNA binding. Similarly, most of the biological process of these genes involves regulation of transcription and these genes are mostly located inside the nucleus as presented in the cellular component category.

Tissue-specific expression profile analysis of alfalfa bZIPs

After analysis of publicly available RNA-Seq data (O'Rourke et al., 2015), we found differential expression of $177 \mathrm{bZIP}$ genes. These genes were selected for having expression values in at least one of the tissues: stem, flowers, leaves, root nodules, roots, and pre-elongated stems (PES). They were then displayed in a heatmap to visualize the expression profile in different tissues and organs (Figure 5). Differential gene expression was observed for different developmental stages. Most of the genes were highly expressed in nodules and roots. Apart from nodules and roots, genes that were upregulated in one developmental stage were downregulated in other developmental stages which can be observed in the heatmap. Even within a group, the genes were differentially expressed across all developmental stages suggesting different $b Z I P$ genes are required for growth and development at different stages. 


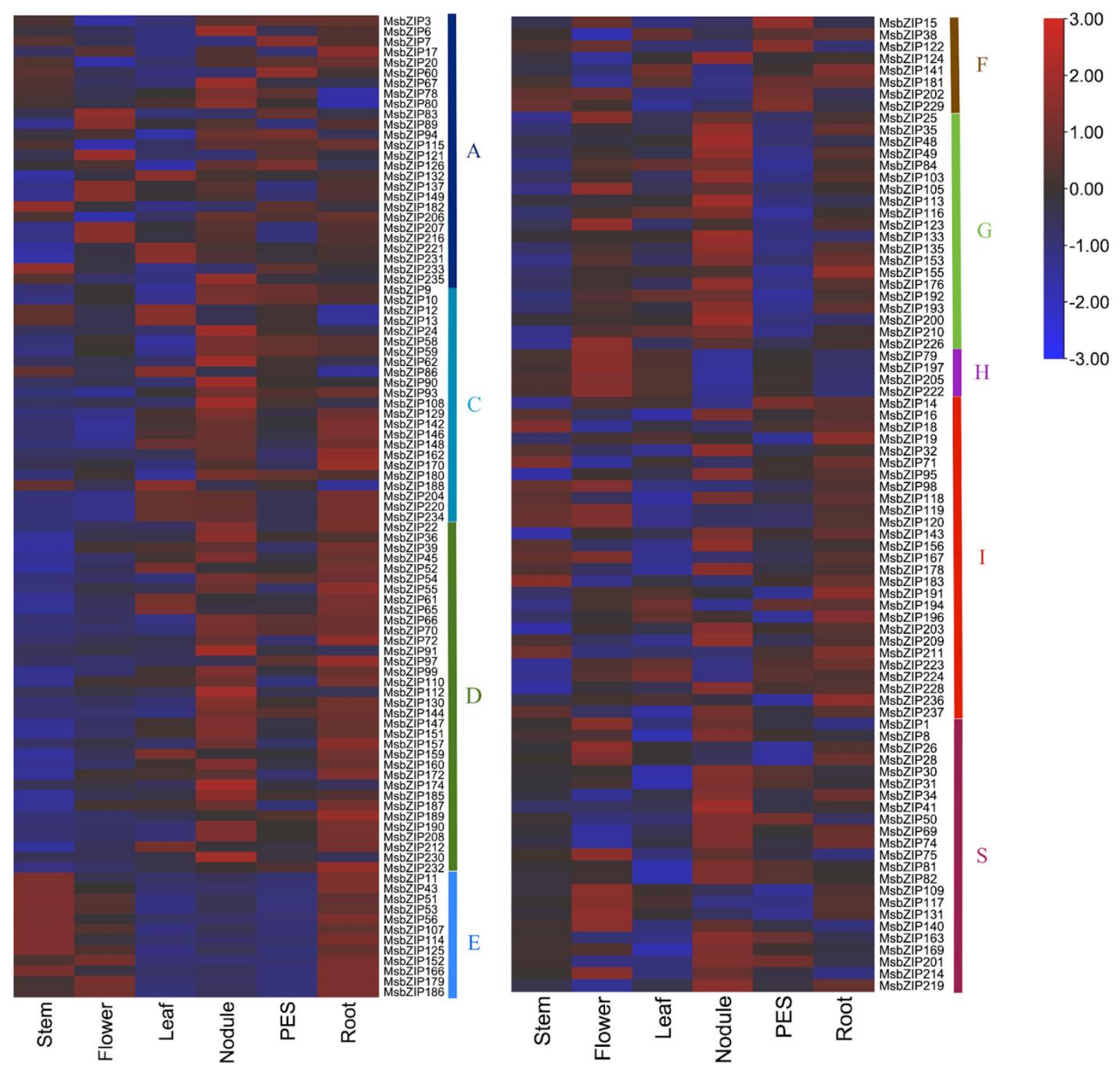

Figure 5: Expression profile of alfalfa bZIP genes among different tissues and organs. In the figure, PES is pre-elongated stem. Most of the genes were highly expressed in Stem, Flower, Leaf, Nodules, Preelongated stem (PES) and Root. The genes that were expressed in one tissue were not expressed in the other tissue indicating different genes may be required during different growth stages of alfalfa. Different groups are represented to the side of the genes by the respective group name along with the color as represented in the phylogenetic tree.

\section{Alfalfa bZIP genes are differentially expressed in response to abiotic stresses}

Analysis from the publicly available RNA-seq datasets showed differential expression of 146 genes during ABA, drought, and salt stress as well as 152 bZIP proteins during cold stress at 0,2 , 6,24 , and 48h, respectively. The expression pattern of MsbZIP genes during different abiotic stress conditions of cold, ABA, drought and salt showed differential expression. Across different time points of abiotic stress, the expression was different for different genes and even within a group the genes were expressed differently for different abiotic stress. Among 4 different time points of cold treatment ( $2 \mathrm{~h}, 6 \mathrm{~h}, 24 \mathrm{~h}$ and $48 \mathrm{~h}$ ), different genes were upregulated at different time points (Supplementary Figure 2). Even within a group, at different time points, different genes were 
upregulated and downregulated at different intervals of cold treatment. Similar to the cold treatment, abiotic stress of $\mathrm{ABA}$, drought and salt treatment also showed multiple genes upregulated at different time points of stress treatment (Figure 6). However, no genes were actively expressed during different time points of the same treatment condition among ABA, drought, and salt, which indicates different transcription factors are active during different abiotic stress as well as different time points of stress.

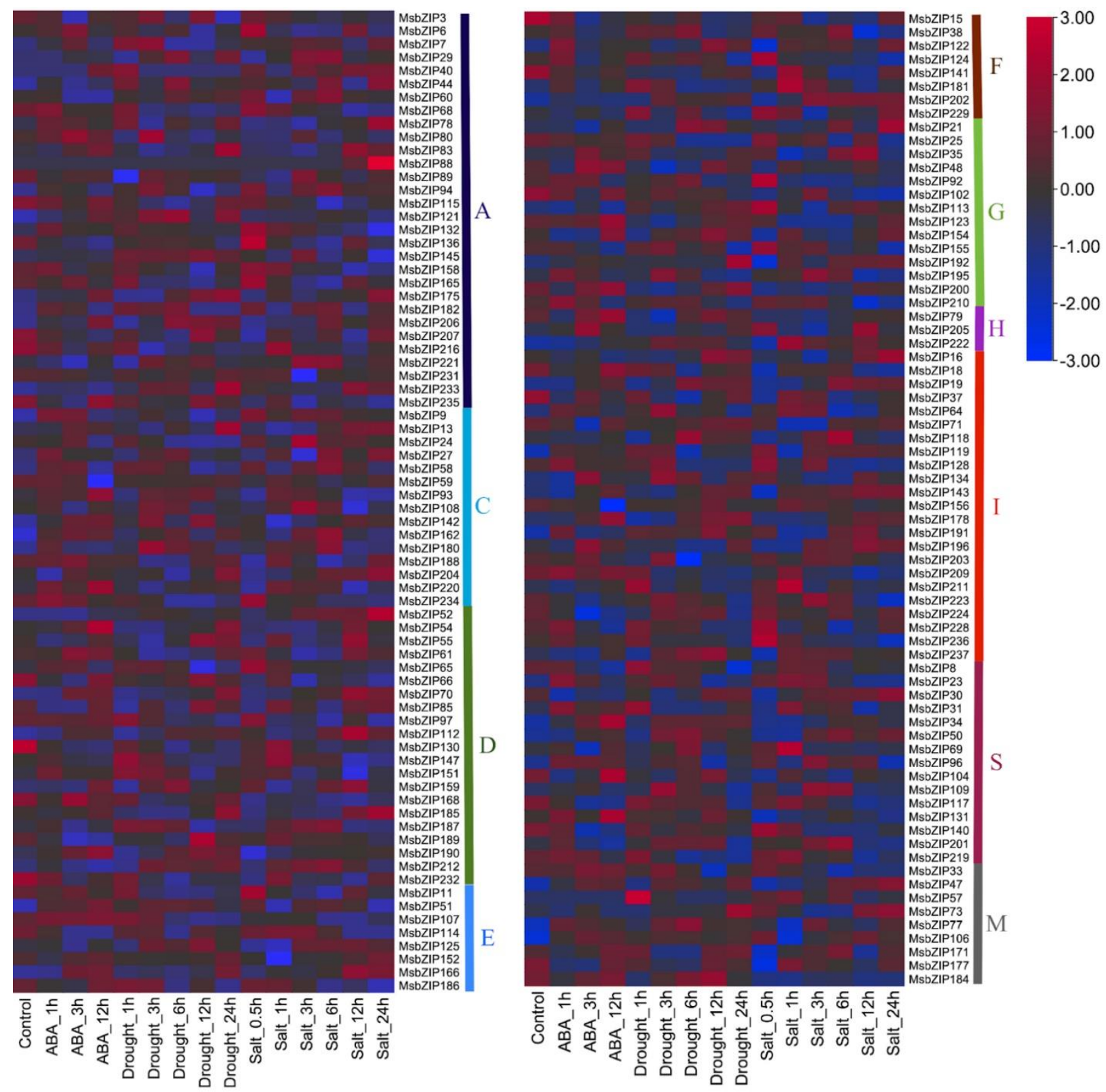

Figure 6. Expression profile of 146 alfalfa bZIP genes in response to ABA, drought, and salt stress. Most of the genes were highly expressed during initial treatment of salt stress from 0.5 to 3 hours. For salt stress, the genes that were highly expressed during the 0.5 hour of treatment were also actively expressed during 3 hours of treatment. For drought stress, gene expression levels were increased as the duration of drought stress was increased from 1 hour to 3 hours to 6 hour and more genes were expressed during 6 hour of drought stress. ABA treatment showed only a few genes that were expressed as the stress duration was increased to 3 hours and 12 hours. Different groups are represented to the side of the genes by the respective group name along with the color as represented in the phylogenetic tree 
Cis-reguatory elements in bZIP gene promoter

The expression pattern of stress responsive-genes are often controlled by cis-regulatory elements. These elements are typically located 5' upstream of the gene coding sequences. These elements provide a binding site for the transcription factors to switch on or off the gene based on the environmental condition. In this study, we analyzed 135 stress-responsive bZIP promoters, we identified 875 cis-regulatory elements distributed along these 135 bZIP promoter. The detailed distribution of these cis-elements along the bZIP promoters was performed (Supplementary Figure 3). We focused on cis-elements implicated in abiotic stress responses and found an abundance of the following cis-regulatory elements: abscisic acid responsive element (ABRE), methyl jasmonate responsive motif (CGTCA-motif), light inducible G-box motif, low-temperature responsive (LTR), drought responsive (MBS binding site) and defense and stress responsive (TCrich repeats).Among the 875 cis-elements, light inducing G-box motif was the highest with 274 followed by abscisic stress responsive element (ABRE) with 234 while low temperature responsive (LTR) with 50 was the lowest.

\section{Discussion}

In the present study, we identified 237 bZIP sequences from tetraploid alfalfa that contained both a highly conserved basic region and the heptad repeat leucine zipper region, suggesting they are functional bZIPs. As predicted, the number of bZIP in tetraploid alfalfa (237) is more than double to that of diploid model legume Medicago truncatula (75). Not surprisingly, the number of bZIP genes varied amongst plant species with Arabidopsis thaliana (78), Lotus japonicus (70), Medicago truncatula (75) and Oryza sativa (89) (E et al., 2014; Jakoby et al., 2002; Z. Wang et al., 2015; Zhang et al., 2015; Pérez-Rodríguez et al., 2010). Similarly, the allotetraploid B. napus genome contained 247 bZIP genes, which is roughly double that of the number found in the related diploid A. thaliana.

Based on phylogenetic analysis and previous analyses from A. thaliana, Medicago truncatula, Lotus japonicus and Oryza sativa, we classified the alfalfa bZIP genes into 10 groups (A, C, D, E, F, G, H, I, M, and S). The most recent classification of bZIPs from A. thaliana (Dröge-Laser et al., 2018) sorted AtbZIPs into 13 groups. Notably, groups B, J and K are missing in our analysis of alfalfa. In A.thaliana there are three members of group B (bZIP17, bZIP28, and bZIP49) and one group $\mathrm{K}$ member (bZIP60), which are implicated in endoplasmic reticulum stress responses (Howell, 2013), but both these groups are missing in alfalfa which begs the question of which groups perform this function in alfalfa. Group $\mathrm{J}$ in A. thaliana is made up of a single copy gene, bZIP62, which is related to Group G bZIP GBF1- a negative regulator of blue-light responsive hypotocol growth that acts antagonistically to HY5 and HYH, two group H bZIPs important in photomorphogenic growth (Gangappa et al., 2013). Another remarkable difference between groups is the group M bZIP72, which is single copy in A. thaliana but contains 13 members in alfalfa. It will be interesting to determine the role $\mathrm{M}$ group bZIPs play in alfalfa and it is intriguing to postulate why this group has increased in number.

It is well established that bZIP transcription factors have a myriad of roles in plant development such as seed maturation and germination (Toh et al., 2012), floral induction and development (Abe et al., 2005; Iven et al., 2010). Not surprisingly, tissue-specific expression of 177 bZIP genes in nodules, flowers, roots, leaves, and stems was found in alfalfa as well (Fig. 5). Interestingly, group E members were most specifically expressed in stems, roots, and flowers, whereas several group F members were expressed in pre-elongated stems. In A. thaliana the group E member bZIP34 has 
been linked to pollen germination and pollen tube growth (Gibalová et al., 2009). In contrast, group F members regulate zinc ( $\mathrm{Zn}$ ) transporters and salt stress responses (Assuncao et al., 2010; O. Yang et al., 2009). Group C and S bZIPs are known to heterodimerize in the so-called C/S1 bZIP network involved in nutrient and energy metabolism (Ehlert et al., 2006; Weltmeier et al., 2006). Likewise, group $\mathrm{C}$ and $\mathrm{S}$ bZIPs are co-expressed in some tissues such as roots and nodules in alfalfa.

In addition to regulating development, bZIPs play a wide array of roles in biotic and abiotic stress responses (Jakoby et al., 2002; Wei et al., 2012) in different crop species. Zou et al., (2008) identified the OsABI5 bZIP TF that was involved in rice fertility and stress tolerance. Nijhawan et al., (2008) related bZIP genes in rice to drought tolerance through genomic survey and gene expression analysis. Similarly, a root-specific bZIP transcription factor was isolated in tepary beans and found to be responsive to water-stress conditions (Rodriguez-Uribe \& O'Connell, 2006). Liao et al., (2008) isolated three bZIP genes (GmbZIP44, GmbZIP62, GmbZIP78) and found a negative regulator of $\mathrm{ABA}$ and tolerance to salt and freezing stress by over-expression in $A$. thaliana. As several studies have shown the role of bZIP transcription factors in the response to plant stress, Liu et al., (2012) further added to it by cloning a bZIP gene and measuring physiological changes mediated by it in alfalfa under different stress conditions. Additionally, they over-expressed cloned alfalfa bZIP genes in tobacco plants which resulted in transgenic tobacco plants conveying salt and drought tolerance. These results indicate that over-expression of certain $b Z I P$ genes increases tolerance of plants to different abiotic stresses. In the present study, MsbZIP genes were found to be differentially expressed in response to cold, ABA, drought and salt indicating the involvement of distinct bZIPs in response to abiotic stresses. Notably, group A MsbZIP88 was strongly upregulated in response to 24h salt stress and in Arabidopsis group A members are involved in ABA signaling and abiotic stress responses. Similarly, another group A member MsbZIP80 showed upregulation 3h of ABA treatment as well as $3 \mathrm{~h}$ drought exposure. Our results are in line with previously published work on bZIPs in abiotic stress responses and provide candidates for functional analyses in alfalfa.

\section{Conclusion}

Here we report the first comprehensive analysis of the bZIP transcription factor family in alfalfa (Medicago sativa). We identified 237 bZIP genes and named them MsbZIP1 to MsbZIP237. Phylogenetic analysis of these bZIP genes using Arabidopsis thaliana as reference divided the sequences into 10 groups, with $\mathrm{B}, \mathrm{J}$, and $\mathrm{K}$ missing in alfalfa. The physico-chemical analysis and motif analysis showed high specificity within each group. The expression profile of bZIPs from suggest bZIPs are expressed in a tissue-specific manner. Finally, the expression profiles of bZIP genes during different abiotic stress conditions (cold, ABA, drought, and salt) showed specific response of a few bZIP at specific timepoints during the stress response making them good candidates for stress-responsive transcription factors. Taken together, this work provides a framework for the future study of bZIPs in alfalfa and presents candidate bZIPs involved in stress-response signaling. 


\section{References}

Abe, M., Kobayashi, Y., Yamamoto, S., Daimon, Y., Yamaguchi, A., Ikeda, Y., Ichinoki, H., Notaguchi, M., Goto, K., \& Araki, T. (2005). FD, a bZIP Protein Mediating Signals from the Floral Pathway Integrator FT at the Shoot Apex. Science, 309(5737), 1052-1056. https://doi.org/10.1126/science.1115983

Altschul, S. F., Gish, W., Miller, W., Myers, E. W., \& Lipman, D. J. (1990). Basic local alignment search tool. Journal of Molecular Biology, 215(3), 403-410. https://doi.org/10.1016/S0022-2836(05)80360-2

Amir Hossain, M., Lee, Y., Cho, J.-I., Ahn, C.-H., Lee, S.-K., Jeon, J.-S., Kang, H., Lee, C.-H., An, G., \& Park, P. B. (2010). The bZIP transcription factor OsABF1 is an ABA responsive element binding factor that enhances abiotic stress signaling in rice. Plant Molecular Biology, 72(4-5), 557-566. https://doi.org/10.1007/s11103-009-9592-9

Assuncao, A. G. L., Herrero, E., Lin, Y.-F., Huettel, B., Talukdar, S., Smaczniak, C., Immink, R. G. H., van Eldik, M., Fiers, M., Schat, H., \& Aarts, M. G. M. (2010). Arabidopsis thaliana transcription factors bZIP19 and bZIP23 regulate the adaptation to zinc deficiency. Proceedings of the National Academy of Sciences, 107(22), 10296-10301. https://doi.org/10.1073/pnas.1004788107

Baena-González, E., Rolland, F., Thevelein, J. M., \& Sheen, J. (2007). A central integrator of transcription networks in plant stress and energy signalling. Nature, 448(7156), 938-942. https://doi.org/10.1038/nature06069

Bailey, T. L., Boden, M., Buske, F. A., Frith, M., Grant, C. E., Clementi, L., Ren, J., Li, W. W., \& Noble, W. S. (2009). MEME SUITE: tools for motif discovery and searching. Nucleic Acids Research, 37(Web Server), W202-W208. https://doi.org/10.1093/nar/gkp335

Bailey, Timothy L., Johnson, J., Grant, C. E., \& Noble, W. S. (2015). The MEME Suite. Nucleic Acids Research, 43(W1), W39-W49. https://doi.org/10.1093/nar/gkv416

Baloglu, M. C., Eldem, V., Hajyzadeh, M., \& Unver, T. (2014). Genome-Wide Analysis of the bZIP Transcription Factors in Cucumber. PLoS ONE, 9(4), e96014. https://doi.org/10.1371/journal.pone.0096014

Carelli, M., Gnocchi, S., Fancelli, S., Mengoni, A., Paffetti, D., Scotti, C., \& Bazzicalupo, M. (2000). Genetic Diversity and Dynamics of Sinorhizobium meliloti Populations Nodulating Different Alfalfa Cultivars in Italian Soils. Applied and Environmental Microbiology, 66(11), 4785-4789. https://doi.org/10.1128/AEM.66.11.4785-4789.2000

Chen, C., Chen, H., Zhang, Y., Thomas, H. R., Frank, M. H., He, Y., \& Xia, R. (2020). TBtools: An Integrative Toolkit Developed for Interactive Analyses of Big Biological Data. Molecular Plant, 13(8), 1194-1202. https://doi.org/10.1016/j.molp.2020.06.009

Chen, Haitao, Zeng, Y., Yang, Y., Huang, L., Tang, B., Zhang, H., Hao, F., Liu, W., Li, Y., Liu, Y., Zhang, X., Zhang, R., Zhang, Y., Li, Y., Wang, K., He, H., Wang, Z., Fan, G., Yang, H., ... Qiu, Q. (2020a). Allele-aware chromosome-level genome assembly and efficient transgene-free genome editing for the autotetraploid cultivated alfalfa. Nature Communications, 11(1), 2494. https://doi.org/10.1038/s41467-020-16338-X

Chen, Haitao, Zeng, Y., Yang, Y., Huang, L., Tang, B., Zhang, H., Hao, F., Liu, W., Li, Y., Liu, Y., Zhang, X., Zhang, R., Zhang, Y., Li, Y., Wang, K., He, H., Wang, Z., Fan, G., Yang, H., ... Qiu, Q. (2020b). Allele-aware chromosome-level genome assembly and efficient transgene-free genome editing for the autotetraploid cultivated alfalfa. Nature Communications, 11(1), 2494. https://doi.org/10.1038/s41467-020-16338-x

Chen, Hao, Chen, W., Zhou, J., He, H., Chen, L., Chen, H., \& Deng, X. W. (2012). Basic leucine zipper transcription factor OsbZIP16 positively regulates drought resistance in rice. Plant 
Science, 193-194, 8-17. https://doi.org/10.1016/j.plantsci.2012.05.003

Chuang, C.-F., Running, M. P., Williams, R. W., \& Meyerowitz, E. M. (1999). The

PERIANTHIA gene encodes a bZIP protein involved in the determination of floral organ number in Arabidopsis thaliana. Genes \& Development, 13(3), 334-344.

https://doi.org/10.1101/gad.13.3.334

Ciceri, P., Locatelli, F., Genga, A., Viotti, A., \& Schmidt, R. J. (1999). The Activity of the Maize Opaque2 Transcriptional Activator Is Regulated Diurnally. Plant Physiology, 121(4), 13211327. https://doi.org/10.1104/pp.121.4.1321

Conesa, A., \& Götz, S. (2008). Blast2GO: A Comprehensive Suite for Functional Analysis in Plant Genomics. International Journal of Plant Genomics, 2008, 1-12. https://doi.org/10.1155/2008/619832

Donnarumma, F., Bazzicalupo, M., Blažinkov, M., Mengoni, A., Sikora, S., \& Babić, K. H. (2014). Biogeography of Sinorhizobium meliloti nodulating alfalfa in different Croatian regions. Research in Microbiology, 165(7), 508-516.

https://doi.org/10.1016/j.resmic.2014.06.001

Dröge-Laser, W., Snoek, B. L., Snel, B., \& Weiste, C. (2018). The Arabidopsis bZIP transcription factor family - an update. Current Opinion in Plant Biology, 45, 36-49. https://doi.org/10.1016/j.pbi.2018.05.001

E, Z. G., Zhang, Y. P., Zhou, J. H., \& Wang, L. (2014). Mini Review Roles of the bZIP gene family in rice. Genetics and Molecular Research, 13(2), 3025-3036. https://doi.org/10.4238/2014.April.16.11

Edgar, R. C. (2004). MUSCLE: multiple sequence alignment with high accuracy and high throughput. Nucleic Acids Research, 32(5), 1792-1797. https://doi.org/10.1093/nar/gkh340

Ehlert, A., Weltmeier, F., Wang, X., Mayer, C. S., Smeekens, S., Vicente-Carbajosa, J., \& Dröge-Laser, W. (2006). Two-hybrid protein-protein interaction analysis in Arabidopsis protoplasts: establishment of a heterodimerization map of group $\mathrm{C}$ and group $\mathrm{S}$ bZIP transcription factors. The Plant Journal, 46(5), 890-900. https://doi.org/10.1111/j.1365313X.2006.02731.X

Freese, N. H., Norris, D. C., \& Loraine, A. E. (2016). Integrated genome browser: visual analytics platform for genomics. Bioinformatics, 32(14), 2089-2095. https://doi.org/10.1093/bioinformatics/btw069

Fu, Z. Q., \& Dong, X. (2013). Systemic Acquired Resistance: Turning Local Infection into Global Defense. Annual Review of Plant Biology, 64(1), 839-863. https://doi.org/10.1146/annurev-arplant-042811-105606

Fukazawa, J., Sakai, T., Ishida, S., Yamaguchi, I., Kamiya, Y., \& Takahashi, Y. (2000). REPRESSION OF SHOOT GROWTH, a bZIP Transcriptional Activator, Regulates Cell Elongation by Controlling the Level of Gibberellins. The Plant Cell, 12(6), 901-915. https://doi.org/10.1105/tpc.12.6.901

Gangappa, S. N., Srivastava, A. K., Maurya, J. P., Ram, H., \& Chattopadhyay, S. (2013). Z-Box Binding Transcription Factors (ZBFs): A New Class of Transcription Factors in Arabidopsis Seedling Development. Molecular Plant, 6(6), 1758-1768. https://doi.org/10.1093/mp/sst140

Gatz, C. (2013). From Pioneers to Team Players: TGA Transcription Factors Provide a Molecular Link Between Different Stress Pathways. Molecular Plant-Microbe Interactions ${ }^{\circledR}, 26(2), 151-159$. https://doi.org/10.1094/MPMI-04-12-0078-IA

Gibalová, A., Reňák, D., Matczuk, K., Dupl'áková, N., Cháb, D., Twell, D., \& Honys, D. (2009). AtbZIP34 is required for Arabidopsis pollen wall patterning and the control of several metabolic pathways in developing pollen. Plant Molecular Biology, 70(5), 581-601. https://doi.org/10.1007/s11103-009-9493-y 
Guan, Y., Ren, H., Xie, H., Ma, Z., \& Chen, F. (2009). Identification and characterization of bZIP-type transcription factors involved in carrot ( Daucus carota L.) somatic embryogenesis. The Plant Journal, 60(2), 207-217. https://doi.org/10.1111/j.1365313X.2009.03948.X

Hossain, M. A., Cho, J.-I., Han, M., Ahn, C.-H., Jeon, J.-S., An, G., \& Park, P. B. (2010). The ABRE-binding bZIP transcription factor OsABF2 is a positive regulator of abiotic stress and ABA signaling in rice. Journal of Plant Physiology, 167(17), 1512-1520. https://doi.org/10.1016/j.jplph.2010.05.008

Howell, S. H. (2013). Endoplasmic Reticulum Stress Responses in Plants. Annual Review of Plant Biology, 64(1), 477-499. https://doi.org/10.1146/annurev-arplant-050312-120053

Hurst, H. C. (1994). Transcription factors. 1: bZIP proteins. Protein Profile, 1(2), 123-168. http://www.ncbi.nlm.nih.gov/pubmed/8528902

Iven, T., Strathmann, A., Böttner, S., Zwafink, T., Heinekamp, T., Guivarc'h, A., Roitsch, T., \& Dröge-Laser, W. (2010). Homo- and heterodimers of tobacco bZIP proteins counteract as positive or negative regulators of transcription during pollen development. The Plant Journal, no-no. https://doi.org/10.1111/j.1365-313X.2010.04230.x

Izawa, T., Foster, R., Nakajima, M., Shimamoto, K., \& Chua, N. H. (1994). The rice bZIP transcriptional activator RITA-1 is highly expressed during seed development. The Plant Cell, 6(9), 1277-1287. https://doi.org/10.1105/tpc.6.9.1277

Jakoby, M., Weisshaar, B., Dröge-Laser, W., Vicente-Carbajosa, J., Tiedemann, J., Kroj, T., \& Parcy, F. (2002). bZIP transcription factors in Arabidopsis. Trends in Plant Science, 7(3), 106-111. https://doi.org/10.1016/S1360-1385(01)02223-3

Ji, X., Liu, G., Liu, Y., Zheng, L., Nie, X., \& Wang, Y. (2013). The bZIP protein from Tamarix hispida, ThbZIP1, is ACGT elements binding factor that enhances abiotic stress signaling in transgenic Arabidopsis. BMC Plant Biology, 13(1), 151. https://doi.org/10.1186/1471-222913-151

Kim, D., Langmead, B., \& Salzberg, S. L. (2015). HISAT: a fast spliced aligner with low memory requirements. Nature Methods, 12(4), 357-360.

https://doi.org/10.1038/nmeth.3317

Kumar, S., Stecher, G., Li, M., Knyaz, C., \& Tamura, K. (2018). MEGA X: Molecular Evolutionary Genetics Analysis across Computing Platforms. Molecular Biology and Evolution, 35(6), 1547-1549. https://doi.org/10.1093/molbev/msy096

Liao, Y., Zou, H.-F., Wei, W., Hao, Y.-J., Tian, A.-G., Huang, J., Liu, Y.-F., Zhang, J.-S., \& Chen, S.-Y. (2008). Soybean GmbZIP44, GmbZIP62 and GmbZIP78 genes function as negative regulator of ABA signaling and confer salt and freezing tolerance in transgenic Arabidopsis. Planta, 228(2), 225-240. https://doi.org/10.1007/s00425-008-0731-3

Liu, C., Wu, Y., \& Wang, X. (2012). bZIP transcription factor OsbZIP52/RISBZ5: a potential negative regulator of cold and drought stress response in rice. Planta, 235(6), 1157-1169. https://doi.org/10.1007/s00425-011-1564-z

LIU, J.-X., SRIVASTAVA, R., \& HOWELL, S. H. (2008). Stress-induced expression of an activated form of AtbZIP17 provides protection from salt stress in Arabidopsis. Plant, Cell \& Environment, 31(12), 1735-1743. https://doi.org/10.1111/j.1365-3040.2008.01873.x

Liu, J., Chen, N., Chen, F., Cai, B., Dal Santo, S., Tornielli, G. B., Pezzotti, M., \& Cheng, Z.-M. (2014). Genome-wide analysis and expression profile of the bZIP transcription factor gene family in grapevine (Vitis vinifera). BMC Genomics, 15(1), 281. https://doi.org/10.1186/1471-2164-15-281

Lu, G., Gao, C., Zheng, X., \& Han, B. (2009). Identification of OsbZIP72 as a positive regulator of ABA response and drought tolerance in rice. Planta, 229(3), 605-615. https://doi.org/10.1007/s00425-008-0857-3 
Luo, D., Wu, Y., Liu, J., Zhou, Q., Liu, W., Wang, Y., Yang, Q., Wang, Z., \& Liu, Z. (2018). Comparative Transcriptomic and Physiological Analyses of Medicago sativa L. Indicates that Multiple Regulatory Networks Are Activated during Continuous ABA Treatment. International Journal of Molecular Sciences, 20(1), 47. https://doi.org/10.3390/ijms20010047

Luo, D., Zhou, Q., Wu, Y., Chai, X., Liu, W., Wang, Y., Yang, Q., Wang, Z., \& Liu, Z. (2019). Full-length transcript sequencing and comparative transcriptomic analysis to evaluate the contribution of osmotic and ionic stress components towards salinity tolerance in the roots of cultivated alfalfa (Medicago sativa L.). BMC Plant Biology, 19(1), 32. https://doi.org/10.1186/s12870-019-1630-4

Nijhawan, A., Jain, M., Tyagi, A. K., \& Khurana, J. P. (2008). Genomic Survey and Gene Expression Analysis of the Basic Leucine Zipper Transcription Factor Family in Rice. Plant Physiology, 146(2), 323-324. https://doi.org/10.1104/pp.107.112821

O’Rourke, J. A., Fu, F., Bucciarelli, B., Yang, S. S., Samac, D. A., Lamb, J. F. S., Monteros, M. J., Graham, M. A., Gronwald, J. W., Krom, N., Li, J., Dai, X., Zhao, P. X., \& Vance, C. P. (2015). The Medicago sativa gene index 1.2: a web-accessible gene expression atlas for investigating expression differences between Medicago sativa subspecies. BMC Genomics, 16(1), 502. https://doi.org/10.1186/s12864-015-1718-7

Park, S.-H., Jeong, J. S., Lee, K. H., Kim, Y. S., Do Choi, Y., \& Kim, J.-K. (2015). OsbZIP23 and OsbZIP45, members of the rice basic leucine zipper transcription factor family, are involved in drought tolerance. Plant Biotechnology Reports, 9(2), 89-96. https://doi.org/10.1007/s11816-015-0346-7

Pellock, B. J., Cheng, H.-P., \& Walker, G. C. (2000). Alfalfa Root Nodule Invasion Efficiency Is Dependent on Sinorhizobium meliloti Polysaccharides. Journal of Bacteriology, 182(15), 4310-4318. https://doi.org/10.1128/JB.182.15.4310-4318.2000

Pérez-Rodríguez, P., Riaño-Pachón, D. M., Corrêa, L. G. G., Rensing, S. A., Kersten, B., \& Mueller-Roeber, B. (2010). PlnTFDB: updated content and new features of the plant transcription factor database. Nucleic Acids Research, 38(suppl_1), D822-D827. https://doi.org/10.1093/nar/gkp805

Pertea, M., Kim, D., Pertea, G. M., Leek, J. T., \& Salzberg, S. L. (2016). Transcript-level expression analysis of RNA-seq experiments with HISAT, StringTie and Ballgown. Nature Protocols, 11(9), 1650-1667. https://doi.org/10.1038/nprot.2016.095

Pertea, M., Pertea, G. M., Antonescu, C. M., Chang, T.-C., Mendell, J. T., \& Salzberg, S. L. (2015). StringTie enables improved reconstruction of a transcriptome from RNA-seq reads. Nature Biotechnology, 33(3), 290-295. https://doi.org/10.1038/nbt.3122

Robinson, M. D., McCarthy, D. J., \& Smyth, G. K. (2010). edgeR: a Bioconductor package for differential expression analysis of digital gene expression data. Bioinformatics, 26(1), 139140. https://doi.org/10.1093/bioinformatics/btp616

Rodriguez-Uribe, L., \& O’Connell, M. A. (2006). A root-specific bZIP transcription factor is responsive to water deficit stress in tepary bean (Phaseolus acutifolius) and common bean (P. vulgaris). Journal of Experimental Botany, 57(6), 1391-1398. https://doi.org/10.1093/jxb/erj118

Toh, S., McCourt, P., \& Tsuchiya, Y. (2012). HY5 is involved in strigolactone-dependent seed germination in Arabidopsis. Plant Signaling \& Behavior, 7(5), 556-558. https://doi.org/10.4161/psb.19839

Udvardi, M. K., Kakar, K., Wandrey, M., Montanari, O., Murray, J., Andriankaja, A., Zhang, J.Y., Benedito, V., Hofer, J. M. I., Chueng, F., \& Town, C. D. (2007). Legume Transcription Factors: Global Regulators of Plant Development and Response to the Environment. Plant Physiology, 144(2), 538-549. https://doi.org/10.1104/pp.107.098061 
Wang, J., Zhou, J., Zhang, B., Vanitha, J., Ramachandran, S., \& Jiang, S.-Y. (2011). Genomewide Expansion and Expression Divergence of the Basic Leucine Zipper Transcription Factors in Higher Plants with an Emphasis on SorghumF. Journal of Integrative Plant Biology, 53(3), 212-231. https://doi.org/10.1111/j.1744-7909.2010.01017.x

Wang, Z., Cheng, K., Wan, L., Yan, L., Jiang, H., Liu, S., Lei, Y., \& Liao, B. (2015). Genomewide analysis of the basic leucine zipper (bZIP) transcription factor gene family in six legume genomes. BMC Genomics, 16(1), 1053. https://doi.org/10.1186/s12864-015-2258-X

Wei, K., Chen, J., Wang, Y., Chen, Y., Chen, S., Lin, Y., Pan, S., Zhong, X., \& Xie, D. (2012). Genome-Wide Analysis of bZIP-Encoding Genes in Maize. DNA Research, 19(6), 463476. https://doi.org/10.1093/dnares/dss026

Weltmeier, F., Ehlert, A., Mayer, C. S., Dietrich, K., Wang, X., Schütze, K., Alonso, R., Harter, K., Vicente-Carbajosa, J., \& Dröge-Laser, W. (2006). Combinatorial control of Arabidopsis proline dehydrogenase transcription by specific heterodimerisation of bZIP transcription factors. The EMBO Journal, 25(13), 3133-3143. https://doi.org/10.1038/sj.emboj.7601206

Yang, O., Popova, O. V., Süthoff, U., Lüking, I., Dietz, K.-J., \& Golldack, D. (2009). The Arabidopsis basic leucine zipper transcription factor AtbZIP24 regulates complex transcriptional networks involved in abiotic stress resistance. Gene, 436(1-2), 45-55. https://doi.org/10.1016/j.gene.2009.02.010

Yang, Y., Li, J., Li, H., Yang, Y., Guang, Y., \& Zhou, Y. (2019). The bZIP gene family in watermelon: genome-wide identification and expression analysis under cold stress and rootknot nematode infection. PeerJ, 7, e7878. https://doi.org/10.7717/peerj.7878

Yin, Y. (1997). RF2a, a bZIP transcriptional activator of the phloem-specific rice tungro bacilliform virus promoter, functions in vascular development. The EMBO Journal, 16(17), 5247-5259. https://doi.org/10.1093/emboj/16.17.5247

Yoshida, T., Fujita, Y., Sayama, H., Kidokoro, S., Maruyama, K., Mizoi, J., Shinozaki, K., \& Yamaguchi-Shinozaki, K. (2010). AREB1, AREB2, and ABF3 are master transcription factors that cooperatively regulate ABRE-dependent ABA signaling involved in drought stress tolerance and require ABA for full activation. The Plant Journal, 61(4), 672-685. https://doi.org/10.1111/j.1365-313X.2009.04092.x

Zhang, Z., Liu, W., Qi, X., Liu, Z., Xie, W., \& Wang, Y. (2015). Genome-wide identification, expression profiling, and SSR marker development of the bZIP transcription factor family in Medicago truncatula. Biochemical Systematics and Ecology, 61, 218-228. https://doi.org/10.1016/j.bse.2015.06.025

Zhou, Q., Luo, D., Chai, X., Wu, Y., Wang, Y., Nan, Z., Yang, Q., Liu, W., \& Liu, Z. (2018). Multiple Regulatory Networks Are Activated during Cold Stress in Medicago sativa L. International Journal of Molecular Sciences, 19(10), 3169. https://doi.org/10.3390/ijms19103169

Zhou, Y., Xu, D., Jia, L., Huang, X., Ma, G., Wang, S., Zhu, M., Zhang, A., Guan, M., Lu, K., Xu, X., Wang, R., Li, J., \& Qu, C. (2017). Genome-Wide Identification and Structural Analysis of bZIP Transcription Factor Genes in Brassica napus. Genes, 8(10), 288. https://doi.org/10.3390/genes8100288

Zou, M., Guan, Y., Ren, H., Zhang, F., \& Chen, F. (2008). A bZIP transcription factor, OsABI5, is involved in rice fertility and stress tolerance. Plant Molecular Biology, 66(6), 675-683. https://doi.org/10.1007/s11103-008-9298-4 